\title{
Schematic concept formation with linguaform patterns '
}

JOAN HOLLIER AND SELBY H. EVANS TEXAS CHRISTIAN UNIVERSITY

This study extends to linguaform patterns the results of earlier studies of schematic concept formation (SCF) with histoforms. Linguaform patterns were constructed as sequences of syllables into which schemata were introduced by a Markov process which favored the occurrence of chosen pairs of syllables. Different pairings of syllables produced different schemata An oddity task was used to test for SCF; the problem required finding the odd sequence in a set of three sequences, two of which had the same schema. All Ss performed above chance and improved with experience, whether the odd pattern represented a different schema or a random sequence. Performance was equally good with and without knowledge of results.

Schema theory has recently been extended by Evans (1967a) to include the hypothesized process of schematic concept formation (SCF), defined as the development of the ability to assign objects to their corresponding schema families on the basis of only the information derived from perceiving the objects. Previous research (Evans, 1964; Edmonds, Mueller, \& Evans, 1966) has demonstrated SCF with histoform patterns which were produced by a computer program, VARGUS 7 (Evans, $1967 \mathrm{~b})$. The program generates segments of a specialized Markov process having, as elements, the numbers 1 through 7. A schema is introduced by arranging high transitional probabilities so as to favor a particular sequence, termed as the most probable sequence (MPS). The schema is manipulated by changing the MPS.

Histoforms are produced from the output of the VARGUS 7 by mapping the numerical elements into column heights. This mapping relation is obviously another variable which can be manipulated. Moreover, schema theory is not limited to the domain of histoforms. In the present study, following an entertaining suggestion by Bernreuter (1966), the numbers of the original Markov process were mapped (in a one-to-one correspondence) into a set of seven syllables. The schema or MPS thus appears as favored combinations of syllables. We term these sequences linguaforms, but do not mean to imply that they have all of the statistical properties of a language.

Linguaforms offer intriguing possibilities for research because every histoform has an isomorph in the linguaform domain. Consequently, every experiment with histoforms has a dual experiment with linguaforms. It is of interest, then, to ask whether comparable experiments will yield comparable results. The present research represents just such an inquiry in connection with research in SCF.

Two studies have used the oddity task to study the development of the abllity to discriminate between members of different schema families. In both of these studies a trial consisting of presenting $S$ with three histoforms, including two of the same schema and one either of a different schema or of no schema (random). The instructions called for $S$ to pick the pattern which was most different. The first study (Evans \& Edmonds, 1966) included knowledge of results (KR) after each trial, and performance was found to be better when the odd pattern was random than when it was drawn from another schema family. In the second study (Edmonds, Mueller, \& Evans, 1966), all odd patterns were drawn from other schema families; performance was found to be the same after 15 trials, whether $K R$ was provided or not. The present study was designed to replicate the conditions of the above studies using linguaforms which were isomorphic to the histoforms used in those studies. Subjects

The Ss were 80 undergraduate students enrolled in introductory psychology. In each of four sessions, Ss were randomly divided into four experimental groups: $67 \%-\mathrm{KR}$; $0 \%-\mathrm{KR} ; 67 \%-\mathrm{NKR}$; and $0 \%-\mathrm{NKR}$. A different order of presentation was used in each session. Thus the treatment groups were balanced with respect to testing session and order of presentation.

Stimuli

The stimuli were constructed from patterns of numbers generated by the VARGUS 7C which were translated by a computer program into sequences 15 syllables in length, composed of the syllables PA, HA, RO, GE, $\mathrm{KO}, \mathrm{ME}, \mathrm{LA}$, these having been selected from Bernreuter's (1966) list. The program also grouped the syllables into "words" of two to five syllables. A schema, in this study, consisted of a particular set of rules pairing the numbers of the Markov process with the above syllables. Each schema was represented by a different pairing and thus by a different most probable sequence of syllables.

\section{Task and Procedure}

Each S was given a 15 page booklet with three sentences per page. For half the Ss, two sentences were $67 \%$ redundant examples of one schema and the third sentence was a random ordering of the syllables $(0 \%$ redundancy). For the other $\mathrm{Ss}$, the third sentence was a $67 \%$ redundant example of a different schema, the odd schema being randomly chosen for each page from a set of three schemata. The position of the odd member of the trial was randomly determined for each trial and was the same for both the $67 \%$ and $0 \%$ groups.

The Ss were instructed that the booklets contained 


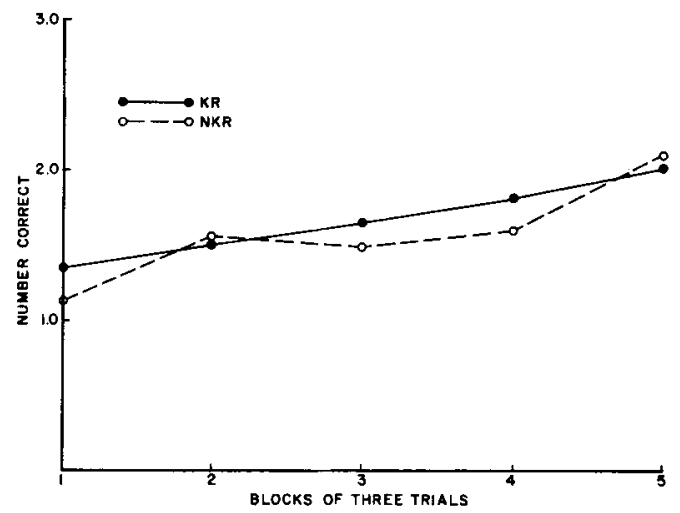

Fig. 1. Mean number of correct responses for blocks of three trials for KR and NKR groups, both averaged over levels of redundancy.

sentences from two different Polynesian languages. Their task was to decide which of the sentences was from the language different from the language of the other two sentences. Each page, a single trial, had the following format:

1. Pagero hako lamepage rohako

2. Merokopage hala meroko page

3. Kopa gerokopa gehala meroko.

In this example, all instances are of $67 \%$ redundancy. Items 2 and 3 are from the same schema and Item 1 is from a different schema.

All Ss had $40 \mathrm{sec}$ for each trial, after which the KR groups were told which instance was correct. The dependent variable was the correct selection of the odd schema.

\section{Results and Discussion}

Inspection of the data indicated that both rate of acquisition and performance level were approximately equal for all groups; therefore, tests for differences between groups were not made. Figure 1 presents performance as a function of three-trial blocks for the KR and NKR conditions (averaged over the redundancy variable). When all groups were combined, a repeated measure test for trend (Winer, 1962) revealed a significant linear trend across trial blocks ( $F=37.58$, df $=1 / 319, p \leq .01$ ).

The significant increase in performance supports the earlier findings that human Ss can learn to distinguish between different schemata as well as between a schema and randomness, even when they are given no information regarding the relevant dimension or dimensions. Thus the results again demonstrate that SCF can occur on the basis of recurrent regularitles in the stimuli themselves. The results also accord with the findings by Shipstone (1960) that when Ss are asked to sort strings of syllables derived from several finite-state grammars, some of them find the patterns induced by these grammars and sort on this basis.

The similar performance of the $67 \%$ and $0 \%$ redundancy groups in this study is in contrast to the findings of Evans \& Edmonds (1966). The absence of a differential effect of KR VB NKR is consistent with the findings of Edmonds, Mueller, \& Evans (1966), but the form of the acquisition curve is somewhat different from the curve found in that study. Thus comparable experiments in the two domains yield results which are grossly similar but different in detail. More generally, the results suggest that linguaforms, and indeed other patterns isomorphic to histoforms, offer a promising means of extending interrelated research.

\section{References}

BERNREUTER, R. G. The dodecalogue of number naming. Amer. Psychol, 1966, 21, 255.

EDMONDS, E. M., MUELLER, M. R., \& EVANS, S. H. Effects of knowledge of results on mixed schema discrimination. Psychon. Sci, 1966, $6,377-378$.

EVANS, S. H. A model for perceptual category formation. Unpublished doctoral dissertation, Texas Christian University, 1964.

EVANS, S. H. A brief statement of schema theory. Psychon. Sci, 1967a, in press.

EVANS, S. H. VARGUS 7: Computed patterns from Markov processes. Behov. Sci, $1967 \mathrm{~b}$, in press.

EVANS, S. H., \& EDMONDS, E. M. Schema discrimination as a function of training. Psychon. Sci, 1966, 5, 303-304.

SHIPSTONE, EVA I. Some variables affecting pattern conception. Psychol Monogr., 1960, 74, No. 17 (Whole No. 504).

WINER, B. J. Statistical principles in experimental design. New York: McGraw-Hill, 1962

Note

1. This research was supported by grant No. TCU/RF 6672 from the TCU research foundation. The second author is responsible for the development of the linguaforms and wishes to acknowledge the contribution of Carl Duncan, whose insightful suggestions initiated the idea. 